\title{
Fake News sobre a Covid-19: como o Discurso Digital em Agências de Fact-Checking Combate a Infodemia
}

\author{
Lafayette B. Melo ${ }^{1}$ \\ ${ }^{1}$ Unidade Acadêmica de Informática - Instituto Federal da Paraíba (IFPB) \\ João Pessoa - PB - Brasil \\ lafayette.melo@ifpb.edu.br
}

\begin{abstract}
This paper investigates the digital discourse of three Fact-Checking Agencies to understand how their discourse is structured in the Covid-19 pandemic. Therefore, the research is supported by assumptions of digital discourse analysis, collecting data integrated with the use of language and computational resources, with a focus on the theme of "early treatment". The features of digital native discourse analysis are used as analysis tools: composite effect, nonlinearity, expansion, investigability, unpredictability and relationality. It is concluded that the expansion feature is not much explored, but the analyzed agencies are embedded in the Web by investigability.
\end{abstract}

Resumo. Este trabalho investiga o discurso digital de três Agências de Checagem de Fatos para compreender como na contemporaneidade o discurso delas é estruturado na pandemia da Covid-19. Para tanto, a pesquisa se ampara em pressupostos da análise do discurso digital, coletando dados integrados ao uso da linguagem e de recursos computacionais, com um recorte no tema do "tratamento precoce". São utilizadas como ferramentas de análise os traços da análise do discurso nativo digital: efeito compósito, deslinearização, ampliação, investigabilidade, imprevisibilidade e relacionalidade. Conclui-se que o traço da ampliação não é muito explorado, mas as agências analisadas estão inseridas na Web pela investigabilidade.

\section{Introdução}

A grande disseminação de fake news tem sido motivo de muita discussão na população e também de estudos (NEVES, 2020; CAMPOS, 2021). As fake news estão dentro do que se chama infodemia, ou seja, uma quantidade tão grande de informações que faz com que não se tenha discernimento sobre o que é falso ou o que é fato. Para Garcia (2020), a infodemia é um grande aumento no volume de informações associadas a um assunto específico, que podem se multiplicar exponencialmente em pouco tempo devido a um evento específico, como na pandemia, e fazer com que surjam rumores, desinformação e manipulação intencional. De modo a denunciar essas informações falsas e mostrar as verdades por trás dos fatos, surgiram as Agências de Checagem de Fatos (Fact Check Agencies), que, conforme Monnerat (2018), têm o intuito de verificar os fatos noticiados, fazendo classificações sobre o grau de veracidade e orientando as pessoas sobre as fontes corretas de obtenção de notícias. Este trabalho investiga o discurso de três Agências de Checagem de Fatos de modo a compreender como o discurso delas é estruturado na pandemia da Covid-19. Para isso, a pesquisa se ampara 
em pressupostos da análise do discurso digital, coletando dados integrados ao uso da linguagem e de recursos computacionais, com recorte no tema do "tratamento precoce".

\section{Fundamentação Teórica}

Os estudos de análise do discurso de linha francesa têm progredido no sentido de abarcarem o efeito do tecnológico na linguagem. Os trabalhos de Paveau $(2013,2018)$ trazem novos conceitos que possibilitam analisar o linguístico e o tecnológico de forma mais integrada, sem deixar de lado preceitos fundamentais da análise do discurso como memória discursiva, historicidade etc. Para a autora, há de se considerar hoje em dia o conceito de tecnologia discursiva, que é aquela representada por ferramentas materiais (base de dados, agendas, sites, ferramentas de busca, entre outras) ou ferramentas não materiais (a linguagem propriamente dita). Tais ferramentas permitem pensar, categorizar, refletir, enfim operar cognitivamente de forma colaborativa entre os humanos. Nesse bojo, a autora também desenvolveu o conceito de discurso nativo digital, aquele que é próprio da Web, produzido no seu interior e expandido a partir da Web 2.0. A autora forneceu aos analistas do discurso ferramentas conceituais de análise, dentre as quais se destacam os traços do discurso nativo digital, assim compreendidos: 1) efeito compósito - discursos digitais são constituídos por matéria mista que reúne indistintamente o linguageiro e o tecnológico em suas diversas modalidades e assim devem ser analisados; 2) deslinearização - discursos não seguem eixos específicos, podem ser quebrados por links; 3) ampliação - discursos têm enunciação ampliada por conta da conversacionalidade da Web Social e podem produzir um enunciador ampliado (que origina uma discussão, mas não mais a detém), e um enunciador coletivo (coproduzindo textos colaborativos em conjunto com as funcionalidades dos sistemas); 4) investigabilidade - os discursos se inscrevem em universos que nada esquecem (são localizáveis e coletáveis) - mesmo aqueles usuários que "apenas" leem as páginas da Web Social deixam inscritos seus rastros, pois a audiência é captada pelos algoritmos; 5) imprevisibilidade - os discursos são parcialmente projetados pelos algoritmos e pelos humanos (o leitor inesperado é aquele que pode fazer diferentes rotas de leitura, escolhendo a ordem de links que desejar e o lurker - o leitor que não se pronuncia, mas acessa tudo - muito menos tem influência total de alguma forma como foi moldado o discurso na interface. Além disso, existe a idiodigitalidade: a idiossincrasia da forma como está configurado o ambiente de cada um, o que torna ainda mais imprevisível saber como as informações são disponibilizadas para o leitor da Web; 6) relacionalidade - os discursos são inscritos em uma relação integrada devido à reticularidade da Web e permitem enunciados coproduzidos com os sistemas.

Há trabalhos que analisam o discurso das Agências de Checagem de Fatos como o de Assis (2020), que identifica como práticas letradas nessas agências são adotadas, em conformidade com princípios de transparência definidos por comissões internacionais. Lelo (2021) analisa o discurso de Agências de Checagem, mas para definir sequências discursivas e os sujeitos implicados na produção do discurso. Este trabalho alia o discurso nativo digital para entender o funcionamento dos discursos nas Agências, tendo como momento histórico a pandemia.

\section{Abordagem Teórico-Metodológica}

Como ferramentas conceituais de análise, foram definidos os traços do discurso nativo digital, propostos por Paveau (2018), mesmo eles não sendo direcionados a analisar 
especificamente fake news ou agências de checagem - atribuição desta pesquisa. Para delimitação do corpus, foram escolhidas três notícias em Agências de Checagem de Fatos com o tema da pandemia. O corpus pôde ser verificado em endereços ${ }^{1}$ respectivamente nos sites E-farsas, Aos Fatos e Boatos.org. Houve uma inspeção inicial com o termo "tratamento precoce" nas ferramentas de busca do site de cada agência, cujas notícias em comum no primeiro resultado de busca de cada site se referiam à cidade de Chapecó. No Google Trends 2 , pesquisando "tratamento precoce" e "chapecó", constatou-se picos nas tendências de busca, respectivamente ao final de março e início de abril, o que sugere alta repercussão sobre notícias deste tratamento com grande discussão, em seguida, sobre o tratamento na cidade mencionada. Tal fato reforçou nossa escolha em estudar como representativos os efeitos do tratamento precoce na cidade de Chapecó. Para verificar a produção dos discursos em função dos lemas e auxiliar no mapeamento da codificação dos links em cada site, foram geradas nuvens de palavras e estruturações dos links e seus agrupamentos com o software ATLAS.ti ${ }^{3}$.

\section{Resultados e Análise}

\subsection{Efeito Compósito}

Observa-se o efeito compósito aliado a um discurso impregnado de textos, banners com propagandas, links para fontes e inserção de figuras e vídeos externos localizados em outros sites e em redes sociais nos três casos. Além disso, e até mais do que as propagandas, há várias chamadas para outras denúncias de fake news em todas as agências. Todas têm ícones para compartilhamento da notícia em diferentes redes sociais. No caso do E-farsas, conforme a figura 1, há chamadas para outras investigações do próprio site como "Jogar videogames faz bem ao cérebro. Verdade ou mito?" entre outras que versam sobre personalidades famosas e mudança de gênero.

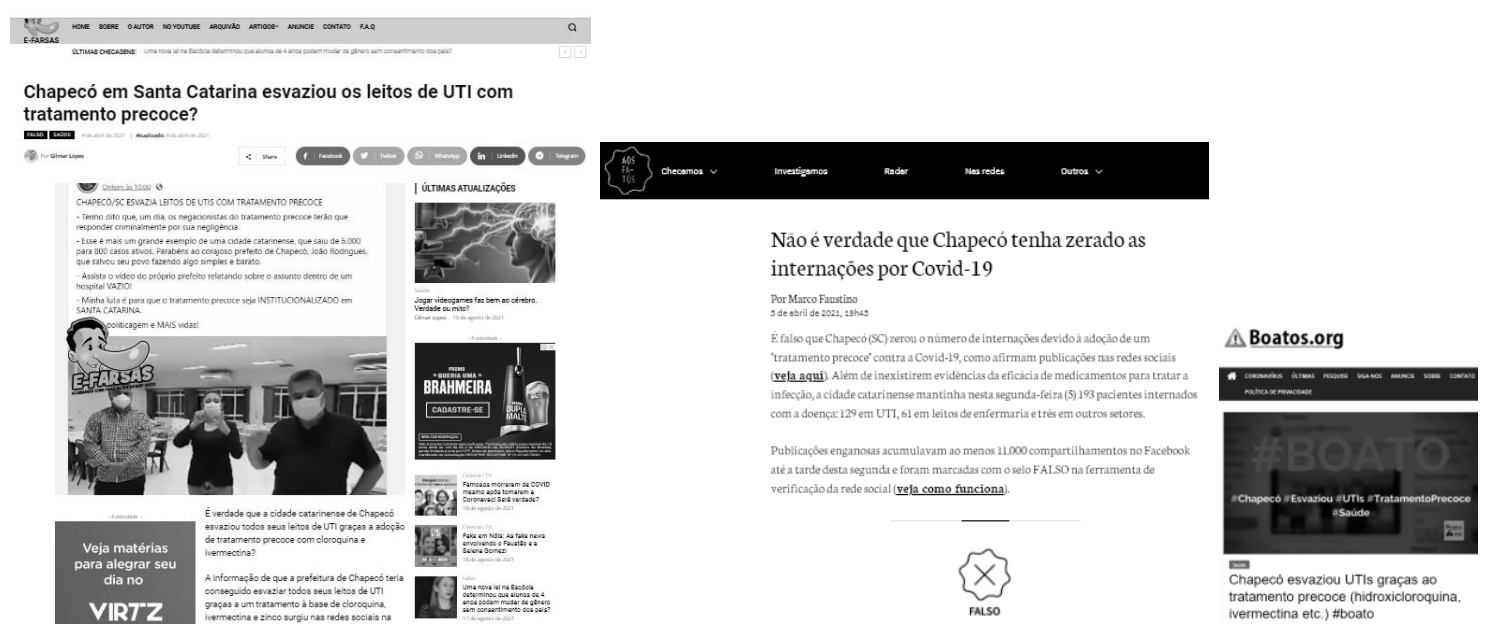

Figura 1. Notícias das Agências de boatos sobre tratamento precoce

\footnotetext{
${ }^{1}$ https://www.e-farsas.com/chapeco-em-santa-catarina-esvaziou-os-leitos-de-utis-com-tratamentoprecoce.html, https://www.aosfatos.org/noticias/nao-e-verdade-que-chapeco-tenha-zerado-internacoespor-covid-19/, https://www.boatos.org/saude/chapeco-esvaziou-utis-tratamento-precoce.html

2 https://trends.google.com.br/trends/?geo=BR

${ }^{3}$ https://atlasti.com/
} 
O único texto que tem algum destaque marcante nas três situações é o título em letras garrafais e negrito e o ritmo da leitura, no corpo do texto, é muitas vezes quebrado abruptamente, seja pelas propagandas ou inserção de mídias. Os ícones para compartilhamento na notícia aparecem no topo da página no caso do E-farsas e do Aos Fatos, mas, no Boatos.org, esses ícones aparecem ao final do texto. O discurso dessas agências se mostra no topo da página como autorreferenciado (com muitas chamadas para o mesmo site) e com links de financiamento de outros serviços, inclusive patrocinados pelo Google Ads.

Mesmo considerando que todo o texto está envolvido por diversas modalidades no efeito compósito, podemos ver como ele em si é distribuído e fizemos nuvens de palavras de acordo com a figura 2, para as várias situações. Pode-se observar que as palavras em destaque nas nuvens também coincidem com palavras nos títulos dos respectivos sites, bem como estão ao lado das chamadas com links, imagens e vídeos. Por exemplo, no site E-farsas, as palavras mais regulares "leitos", "esvaziou", "tratamento", "precoce" e Chapecó" também estão no título e descrevendo imagens ou links para outros sites. O efeito compósito nesses três casos tem a caraterística de empregar palavras que são regulares também no título e ao lado de outras modalidades.
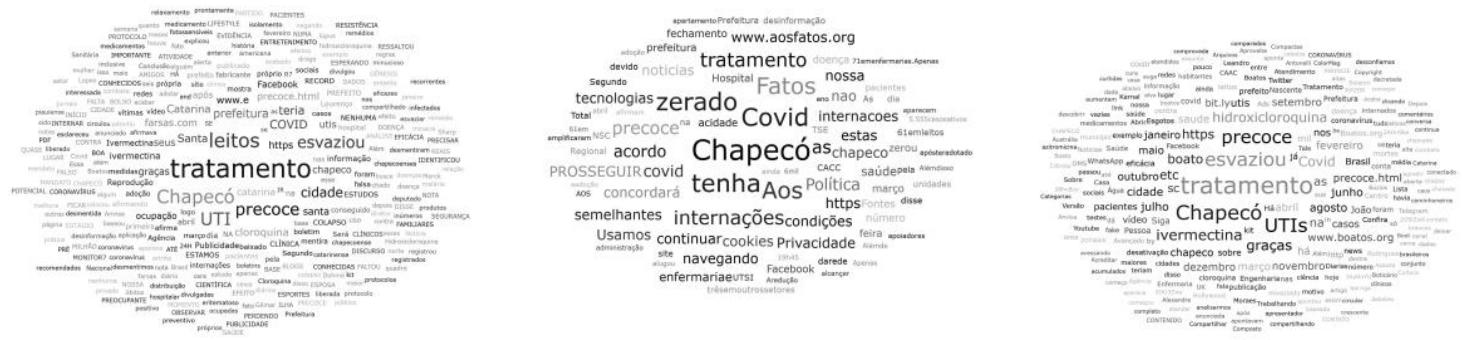

Figura 2. Nuvens de palavras no E-farsas, no Aos Fatos e no Boatos.org

\subsection{Deslinearização}

Há uma distribuição extensa de links em, basicamente, todos os parágrafos, e nos três casos. Há uma distribuição de possibilidades de deslinearização com referência a órgãos oficiais do governo, órgãos de comunicação, órgãos de saúde e para comprovações das frases que geraram os boatos. Na figura 3, os links do site do E-farsas estão representados em códigos gerados pelo ATLAS.ti e com agrupamentos para: 1) duas comprovações das frases fake (uma imagem linkada e inserida na página - mas retirada do Facebook - e um link direto para vídeo do político no seu Facebook); 2) quatro links com informações de órgão governamental (uma imagem do site da prefeitura de Chapecó, um link para o próprio site, um link para um documento PDF retirado do site e um link para o Facebook da prefeitura); 3) quatro links para órgãos de comunicação (site da Agência Brasil, do Jornal do Estado de Minas, da revista Exame e uma outra reportagem do próprio E-farsas); 4) dois links para órgãos que trabalham com saúde (sites da Anvisa e da Merck).

O site do Aos Fatos tem a mesma estrutura para essa reportagem: links para a frase que gerou o boato e órgãos de saúde, comunicação e do governo. O Boatos.org tem essa estrutura e mais um grupo de links que leva a sites de revistas científicas ou órgãos acadêmicos, conforme pode ser comprovado pelos links disponibilizados. 
As tecnologias discursivas possibilitam nesse caso que as Agências de Checagem de Fatos comprovem que a informação é fake não apenas pela disponibilidade de links oficiais, mas com repetições de links para um mesmo site, às vezes com localizações e formatos diferentes e inserção de imagens desses outros locais o que reforça a mensagem que se deseja confirmar. $O$ fato de haver poucos links para revistas acadêmicas e científicas pode se justificar pelo fato de as Agências quererem ter uma discussão menos técnica com o público em geral.

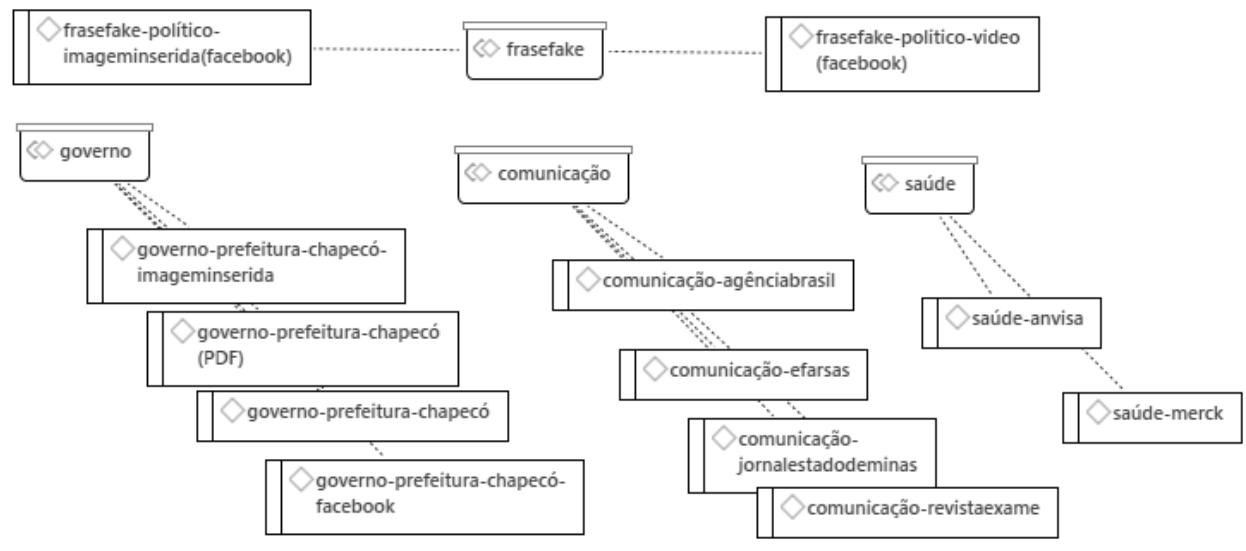

Figura 3. Estrutura dos links no E-farsas em agrupamentos de códigos

\subsection{Ampliação}

A ampliação discursiva não é caracterizada por um enunciador ampliado em nenhuma das situações, mas por um enunciador coletivo e apenas no caso do E-farsas. Ao se averiguar o link, pode-se notar, ao final do texto, um espaço para várias postagens e comentários de postagens aberto ao público, em que tem uma regularidade de falas muito grande reconhecendo o valor da notícia e ao mesmo tempo declarando algo sobre as visões que ainda acreditam no tratamento precoce ("Puxa-sacos do presidente são uma desgraça", "O que mais rola aqui em SC é boatos de tratamentos...", "Claro que é mentira. Tratamento precoce não funciona", "Tenho dito que, um dia, os compartilhadores de boatos sobre hidroxicloroquina e Ivermectina terão que responder criminalmente por sua desinformação", "O desespero dos bovinos é notório. Fabricam mentiras para tentar defender o indefensável..."). Contudo, surgem postagens ou comentários que não dão crédito à denúncia do E-farsas, e denunciam o site e apoiadores de "esquerdista", "comunistas", "petistas" e semelhantes. Parece inevitável haver a ampliação para um discurso de embate político. A título de exemplificação, na figura 4, é extraído um trecho que inicia com ironia sobre a denúncia do E-farsas, menosprezando a figura do jornalista, que não teria autoridade para dizer que o tratamento precoce não funciona, e exaltando a figura do médico. Aparece, então, um comentário que também ironiza, mas valorizando com embuste irônico os cientistas, biólogos e acadêmicos em detrimento dos "seguidores do MINTO". O mediador da discussão, responsável pelo site, reforça que uma cidade elogiada por Bolsonaro no tratamento precoce tem mortalidade maior do que a média nacional. Em seguida, um comentário arremata que há jornalistas que apontam dados e fatos que nenhum médico pode refutar. O responsável pelo site, apesar de mediador, não detém a discussão e surge um enunciador coletivo na ampliação do discurso para aspectos políticos, profissionais ou subentendidos como científicos. Ao se averiguar outras notícias do site, 
verifica-se que o E-farsas sempre deixa espaço aberto para discussões. O que pode se depreender é que, se houver espaço para discussões ampliadas, sempre há reconhecimento do público pela denúncia dos boatos. Contudo também há posicionamentos contrários ao site, não reconhecendo as evidências, mesmo que com várias fontes oficiais, como discutimos anteriormente nos traços de deslinearização.

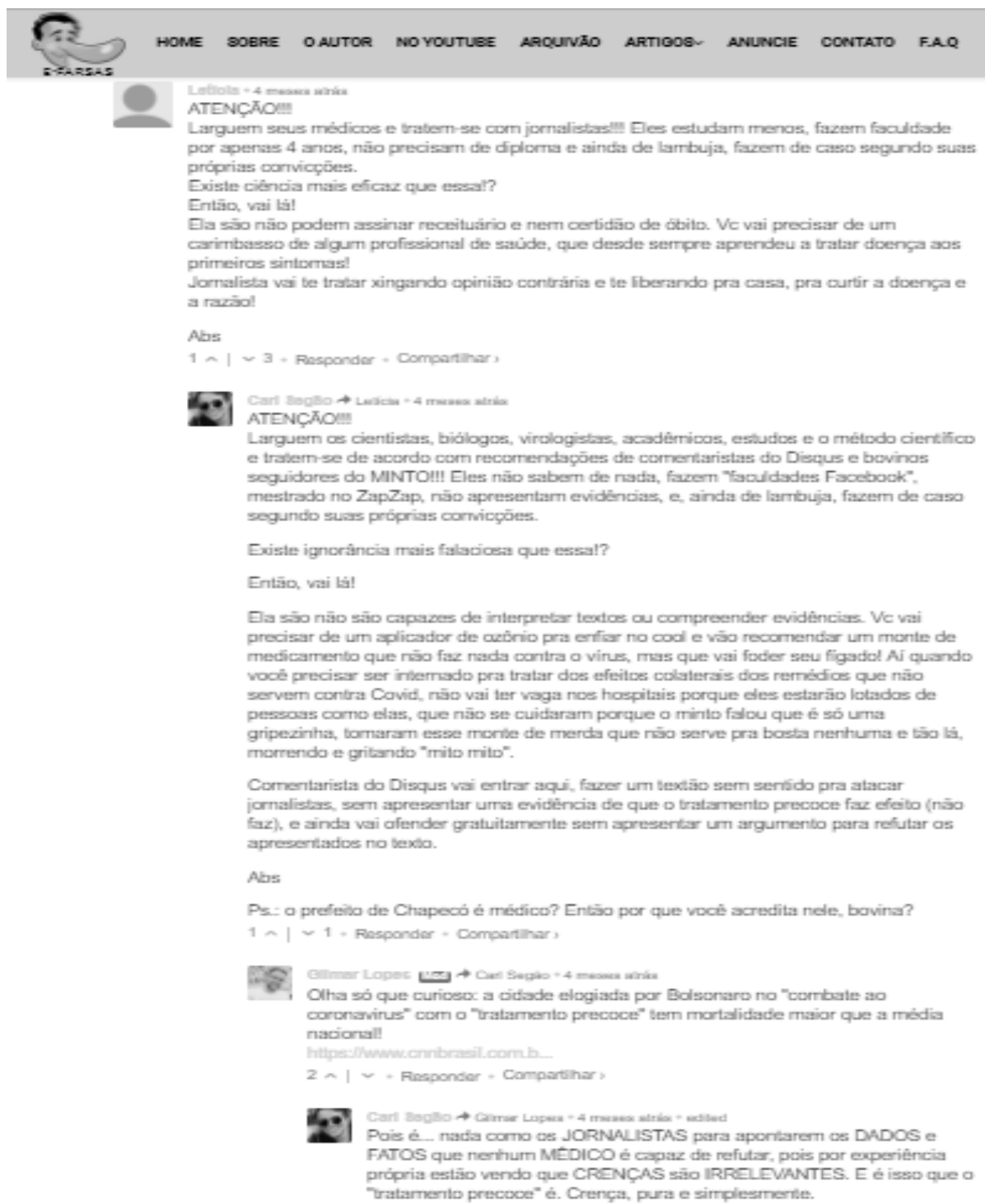

Figure 4. Ampliação discursiva no E-farsas

\subsection{Investigabilidade}

Os traços de que as Agências de Checagem de Fatos têm suas notícias rastreáveis, coletáveis ou replicáveis podem ser vistos em comentários em redes ou referências em outros sites, bem como em resultados de busca no Google. Ao colocarmos o título do Boatos.org ("Chapecó esvaziou UTIs graças ao tratamento precoce (hidroxicloroquina, ivermectina etc.) \#boato") nas buscas do Google, podemos observar uma postagem ${ }^{4}$ da página do Boatos.org no Facebook em que se anuncia reportagem do site com um link

\footnotetext{
${ }^{4}$ https://www.facebook.com/Boatos.org/posts/1905935832887145/
} 
para a notícia original. Com efeito, fazendo este mesmo exercício de busca dos títulos em relação às outras agências, encontramos uma postagem ${ }^{5}$ no Twitter com referência à notícia do Aos Fatos. Colocando o título do E-farsas ("Chapecó em Santa Catarina esvaziou os leitos de UTI com tratamento precoce?") nas buscas do Google, encontramos outra postagem ${ }^{6}$ no Twitter do próprio E-farsas linkada ao site original.

Devido à rastreabilidade e incorporação interna dos metadados nas informações divulgadas na Web, há outras possibilidades de se encontrar referências que com o tempo podem ser replicadas continuamente. Um usuário pode linkar endereços das Agências em qualquer outro site e discutir o que compartilha, ampliando o discurso. Enfim, a denúncia sobre o boato de que Chapecó esvaziou as UTIS com tratamento precoce pode ser mais ou menos compartilhada, conforme o momento histórico, os recursos de divulgação ou rastreamento e dependendo da imprevisibilidade de escrita e leitura na Web conforme veremos adiante.

\subsection{Imprevisibilidade}

A escrita e leitura idiodigital possibilita o inesperado e o diferente para cada usuário, conforme suas práticas e configurações do sistema, o que não é tão destacado assim nos sites das Agências, já que não há tanta personalização ou possibilidade de quebra conversacional (a não ser no caso do E-farsas) e os links verificados levaram exatamente ao que se sugeria nos textos dos hiperlinks (informações oficiais de outros meios de comunicação, órgãos do governo etc.). Mesmo os links para propagandas, que ficam em formatos de banner ou encobrindo alguns textos, têm destaques que se mostram exatamente como propagandas (apelo para compras de novos alimentos, produtos, cartões, novos tratamentos de saúde etc.). O que pode ocorrer é um leitor inesperado costurar links nos sites para não terminar sua leitura no texto, mas em diferentes redes e o lurker possibilitar ranqueamento a mais ou a menos dos sites, dependendo do interesse histórico que se tiver sobre o assunto relatado. Assim, a leitura sobre o boato do tratamento precoce em Chapecó não tem dependência dos projetistas dos sites, mas pode-se estudar as possíveis trajetórias de leitura ou ordenamento de disponibilização da informação para facilitar experiências interpretativas.

\subsection{Relacionalidade}

As relações de várias naturezas nos sites de Agência de Checagem são fortemente marcadas, não apenas pela deslinearização, pela investigabilidade e pela imprevisibilidade, mas pela forma como mostram discursos intercalados. Pudemos já observar nos exemplos anteriores que há um discurso inicial mostrado nos sites, que é o discurso de denúncia de boatos e esclarecimentos sobre fatos não verdadeiros. O site, por si só, é fechado em torno desse tema, mesmo que se abra espaço para discussão, como ocorre no E-farsas, que desencadeia naturalmente outros tipos de discurso relacionados à política, ciência, comunicação, posicionamentos profissionais e ideológicos etc. Outros tecnodiscursos são desencadeados em ligação com vários canais como Facebook, Youtube, Twitter, Instagram, blogs, entre outros, o que faz com que as Agências de Checagem de Fatos, mesmo que não sejam redes sociais ou sistemas

\footnotetext{
${ }^{5} \mathrm{https} / /$ twitter.com/aosfatos/status/1379450406976286721?lang=ar-X-fm

${ }^{6}$ https://twitter.com/efarsas/status/1378730585095598087
} 
colaborativos, estejam inseridas na Web Social, coparticipando com outras pessoas e coproduzindo com outros sistemas novos enunciados de forma encadeada e contínua.

\section{Considerações Finais}

Respondendo à questão de pesquisa inicial "Como o discurso das Agências é estruturado dentro do evento da pandemia da Covid-19?": para o recorte dado, pode-se observar que o traço da ampliação não é muito explorado, mas as agências analisadas estão inseridas na Web Social devido à investigabilidade. O efeito compósito é fundamental para disposição da informação e fluência da leitura. A deslinearização possibilita categorização de links específicos. A relacionalidade atua com os outros traços. As limitações da pesquisa estão no fato de termos um pequeno recorte de dados para um assunto muito específico em uma época determinada e a triangulação dos dados indica que há possibilidades de se fazer novas pesquisas com a mesma metodologia em uma análise vertical para outros assuntos e outros tipos de site que tratem de fake news. Pretende-se ampliar os estudos, integrando-os com o de avaliações de interface para compreender como projetos de interface levariam em conta a experiência discursiva.

\section{Referências}

ASSIS, Juliana Alves; KOMESU, Fabiana; FLUCKIGER, Cédric. Efeitos da Covid-19 em práticas letradas acadêmicas. 2020.

CAMPOS, Lorraine Vilela. "O que são Fake News?"; Brasil Escola. Disponível em: $<$ https://brasilescola.uol.com.br/curiosidades/o-que-sao-fake-news.htm $>$. Acesso em 18 ago. 2021.

GARCIA, Leila Posenato; DUARTE, Elisete. Infodemia: excesso de quantidade em detrimento da qualidade das informações sobre a COVID-19. 2020.

LELO, Thales Vuela; PACHI FILHO, Fernando. Credibilidade em disputa no jornalismo digital: Estrategias discursivas das agencias de fact-checking brasilenas vinculadas aos conglomerados de midia/[es] Credibilidad en disputa en periodismo digital: estrategias discursivas de agencias brasilenas de fact-checking ligadas a los conglomerados de medios/[en] Disputed credibility in digital journalism: discursive strategies of Brazilian fact-checking organizations from media conglomerates. Estudios sobre el Mensaje Periodistico, v. 27, n. 2, p. 531-542, 2021.

MONNERAT, A. A aposta no fact checking: jornalistas criam mais iniciativas para verificar o discurso público e revelar notícias falsas. Sindicato dos Jornalistas Profissionais no Estado de SP, 2018. Disponível em: http://www.sjsp.org.br/noticias/a-aposta-no-fact-checking-f810. Acesso em: 14 nov. 2020.

NEVES, Barbara Coelho; BORGES, Jussara. Por que as fake news têm espaço nas mídias sociais?: uma discussão à luz do comportamento infocomunicacional e do marketing digital. Informação \& Sociedade: estudos. João Pessoa. Vol. 30, n. 2 (abr./jun. 2020), p. 1-22, 2020.

Paveau, M.-A. (2013), Os pré-discursos: sentido, memória, cognição. Pontes.

Paveau, M.-A. (2018), L'analyse du discours numérique: Dictionnaire des formes et des pratiques, Hermann. 